\title{
The history of neurosurgery at the University of Rochester
}

\author{
Historical vignette \\ Kristopher T. Kimmell, M.D., ${ }^{1}$ Anthony L. Petraglia, M.D., ${ }^{1}$ Robert Bakos, M.D., ${ }^{1}$
Thomas Rodenhouse, M.D., ${ }^{1}$ Paul K. Maurer, M.D., ${ }^{2}$
And Webster H. Pilcher, M.D., Ph.D. ${ }^{1}$
}

${ }^{1}$ Department of Neurosurgery, University of Rochester; and ${ }^{2}$ Department of Neurosurgery, Unity Health, Rochester, New York

\begin{abstract}
The Department of Neurosurgery at the University of Rochester has a long legacy of excellent patient care and innovation in the neurosciences. The department's founder, Dr. William Van Wagenen, was a direct pupil of Harvey Cushing and the first president of the Harvey Cushing Society. His successor, Dr. Frank P. Smith, was also a leader in organized neurosurgery and helped to permanently memorialize his mentor with an endowed fellowship that today is one of the most prestigious training awards in neurosurgery. The first 2 chiefs are honored every year by the department with memorial invited lectureships in their names. The department is home to a thriving multidisciplinary research program that fulfills the lifelong vision of its founder, Dr. Van Wagenen.

(http://thejns.org/doi/abs/10.3171/2014.7.JNS132658)
\end{abstract}

KeY Words • history • neurosurgery • legacy

A $S$ the University of Rochester Medical Center (URMC) enters its 9th decade, the Department of Neurosurgery reflects on its legacy. With direct ties to the father of modern neurosurgery, Dr. Harvey Cushing, neurosurgery in Rochester has a long history of being at the forefront of advances in the neurosciences, which continues today (Table 1).

Strong Memorial Hospital, the main teaching hospital of the University of Rochester, delivers specialized care to a region with a population of 2.3 million people. What began as a humble attempt to improve medical education in Western New York is today a nationally renowned medical center that is home to a thriving multidisciplinary neuromedicine program with a full complement of neurosurgical subspecialists and an institute dedicated to basic and translational research in the neurosciences.

\section{The Beginning}

The URMC was established as a response to Abraham Flexner's report in 1910, which found that the education being provided by most medical schools in America was shockingly inadequate. ${ }^{1}$ Flexner's recommendations revolutionized medical education and led to the development of medical schools that emphasized scientific inquiry, learning, and patient care. This philosophy served as

Abbreviation used in this paper: URMC = University of Rochester Medical Center. the foundation for the URMC. With the help of local industrialist and philanthropist George Eastman, the medical school was formed in 1921. Dr. George Hoyt Whipple was selected as the first dean of the medical school and personally oversaw the hiring of faculty and staff as well as the design and construction of the buildings. Whipple, a Johns Hopkins pathologist and colleague of Harvey Cushing, would win the Nobel Prize in Medicine 13 years later in 1934. In 1926, Strong Memorial Hospital opened its doors (Fig. 1).

Many consider October 26, 1926, to be the birth of neurosurgery at the URMC. To commemorate the opening of Strong Memorial Hospital, Whipple invited Cushing, who delivered the first-ever surgical grand rounds at URMC on the topic of tumors and disorders of the pituitary. Many of Cushing's patients from the Rochester area were presented. The clinic was such a success that Whipple wrote Cushing later to tell him he thought that it was the best talk he had ever heard Cushing give. In 1931, Cushing was granted an honorary degree from the University of Rochester.

Neurosurgical procedures at the URMC were initially performed by the first chairman of the Surgery Department, Dr. John J. Morton Jr. (Fig. 2). Dr. Morton had received his surgical training in Boston, including at Peter Bent Brigham Hospital; he was one of Cushing's first house officers in general surgery in Boston. The two had also served in the same unit in the Army Medical Corps during World War I. 
TABLE 1: Timeline for the Department of Neurosurgery at URMC

\begin{tabular}{|c|c|}
\hline Date & Event \\
\hline 1921 & University of Rochester Medical School founded \\
\hline 1926 & Strong Memorial Hospital opens \\
\hline 1926 & $\begin{array}{l}\text { Dr. Harvey Cushing delivers first surgical grand rounds at } \\
\text { URMC }\end{array}$ \\
\hline 1928 & $\begin{array}{l}\text { Dr. William Van Wagenen hired as first chief of neurosurgery at } \\
\text { URMC }\end{array}$ \\
\hline 1931 & $\begin{array}{l}\text { Inaugural meeting of Harvey Cushing Society in Boston, MA; } \\
\text { Dr. Van Wagenen is elected first president of the society }\end{array}$ \\
\hline 1933 & Dr. Roland Bellows is first neurosurgery resident at URMC \\
\hline 1941 & 10th annual Harvey Cushing Society meeting held in Rochester \\
\hline 1948 & $\begin{array}{l}\text { Dr. Frank P. Smith graduates from URMC neurosurgery pro- } \\
\text { gram }\end{array}$ \\
\hline 1954 & $\begin{array}{l}\text { Dr. Van Wagenen retires; Dr. Smith appointed chief of neurosur- } \\
\quad \text { gery }\end{array}$ \\
\hline 1956 & Dr. Joseph McDonald joins Division of Neurosurgery at URMC \\
\hline 1961 & $\begin{array}{l}\text { Dr. Van Wagenen dies, establishes Van Wagenen Fellowship } \\
\text { in his will }\end{array}$ \\
\hline 1964 & $\begin{array}{l}\text { Dr. Shige-Hisa Okawara graduates from URMC neurosurgery } \\
\text { program }\end{array}$ \\
\hline 1964 & $\begin{array}{l}\text { First annual William P. Van Wagenen Visiting Professor at } \\
\text { URMC }\end{array}$ \\
\hline 1974 & Dr. McDonald appointed chief of neurosurgery \\
\hline 1975 & Dr. Okawara returns as faculty to URMC \\
\hline 1980 & Dr. Frank P. Smith Chair in Neurosurgery established \\
\hline 1990 & $\begin{array}{l}\text { Dr. McDonald retires; Dr. Eugene George appointed chief of } \\
\text { neurosurgery at URMC }\end{array}$ \\
\hline 1990 & Dr. Webster Pilcher hired as faculty at URMC \\
\hline 1995 & $\begin{array}{l}\text { Dr. George steps down as chief; Dr. Okawara appointed interim } \\
\text { chief of neurosurgery }\end{array}$ \\
\hline 1997 & First annual Frank P. Smith Visiting Professor at URMC \\
\hline 1998 & Neurosurgery achieves departmental status \\
\hline 1999 & Dr. Robert Maciunas appointed chair of neurosurgery \\
\hline 2001 & Dr. Smith receives the Distinguished Service Award from AANS \\
\hline 2001 & Frank P. Smith Research Laboratories established \\
\hline 2002 & Dr. Pilcher appointed chair of Department of Neurosurgery \\
\hline 2011 & Del Monte Neuromedicine Institute at URMC established \\
\hline
\end{tabular}

\section{William Perrine Van Wagenen (1928-1954)}

In 1928 Dr. William Perrine Van Wagenen joined the surgical staff at the University of Rochester and became the hospital's first specialist in neurosurgery (Fig. 3). Van Wagenen (1897-1961) was a native of upstate New York and attended Cornell University. After a brief stint in the Army he matriculated at Harvard Medical School and graduated in 1923. His internship was at Peter Bent Brigham Hospital, where he trained in both general surgery and neurosurgery under Cushing. It was in Boston where Van Wagenen developed a lifelong relationship with Cushing.

On July 1, 1928, Van Wagenen was appointed as assistant professor of neurological surgery and chief of the neurosurgical service, which was the first mention of the specialty in the URMC medical school catalog. Van Wa-

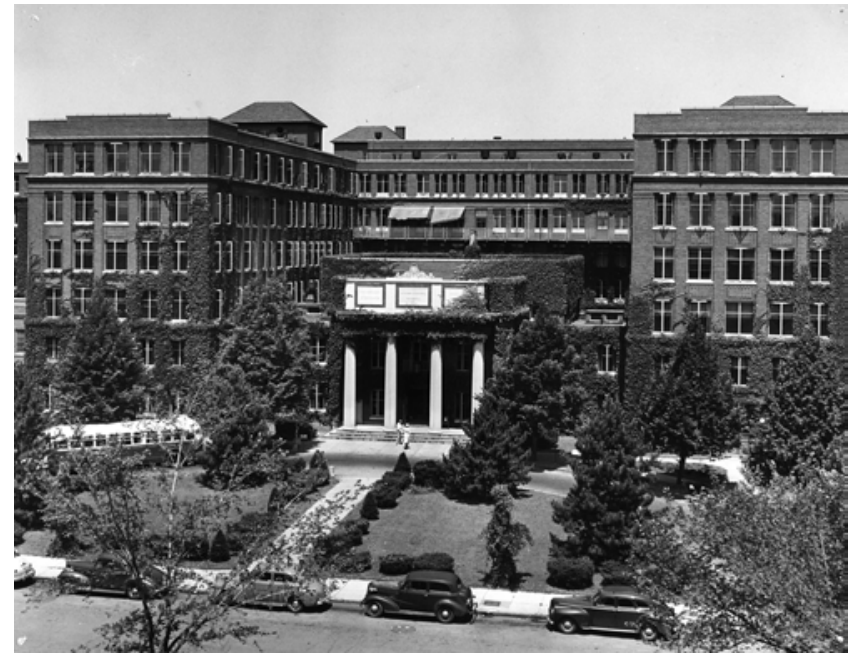

Fig. 1. Photograph of Strong Memorial Hospital, circa 1945. (Image courtesy of the Department of Neurosurgery, URMC.)

genen's early years in Rochester were highly industrious. Van Wagenen was an operative innovator who performed one of the first successful resections of a tumor in the pineal region. ${ }^{7}$ In 1931, with the help of a benefactor, he established a fund to support a research fellow in neurosurgery. This was the first such fund in the Department of Surgery, and aided in the recruitment of trainees from all over the country. By 1933, Van Wagenen had his first clinical trainee in neurosurgery, Roland Bellows. By the mid-1930s there were as many as 3 people in training at any given time. Some residents spent time in Toronto as part of an exchange program run by Dr. Kenneth McKenzie, one of Canada's first neurosurgeons. In 1942 Dr. Van Wagenen left URMC to serve in the US Army. The neurosurgery service was curtailed at that time and did not begin to reexpand until his return after the war. In total, Van Wagenen would train 8 residents in neurosurgery, including his successor, Dr. Frank Pye Smith.

In the early years of neurosurgery as a specialty, Van Wagenen emerged as a leader; he was a driving force in the founding of the Harvey Cushing Society, ${ }^{2,5}$ the precursor of the AANS. At the inaugural meeting of the Harvey Cushing Society, Van Wagenen was named its first president. His inaugural address highlighted the primacy of resident education. The Society's 10th meeting was held at URMC in 1941. At that meeting the URMC neurosurgery service presented work on epilepsy, with descriptions of the first corpus callosotomies performed. ${ }^{3}$ Van Wagenen also made concerted efforts to have Dr. Cushing's brain tumor collection housed in Rochester, corresponding with Cushing and other members of the Harvey Cushing Society regarding the project and securing funding from benefactors. He proposed to Dr. Louise Eisenhardt that she be made the curator of the archive (http://www.neurosurgery. org/cybermuseum/index.html). Unfortunately he was unable to convince the URMC leadership of the value of such a collection and so eventually Cushing's library was housed at Yale. ${ }^{2}$

Van Wagenen, inspired by Wilder Penfield's accomplishment of creating the Montreal Neurological Institute, 


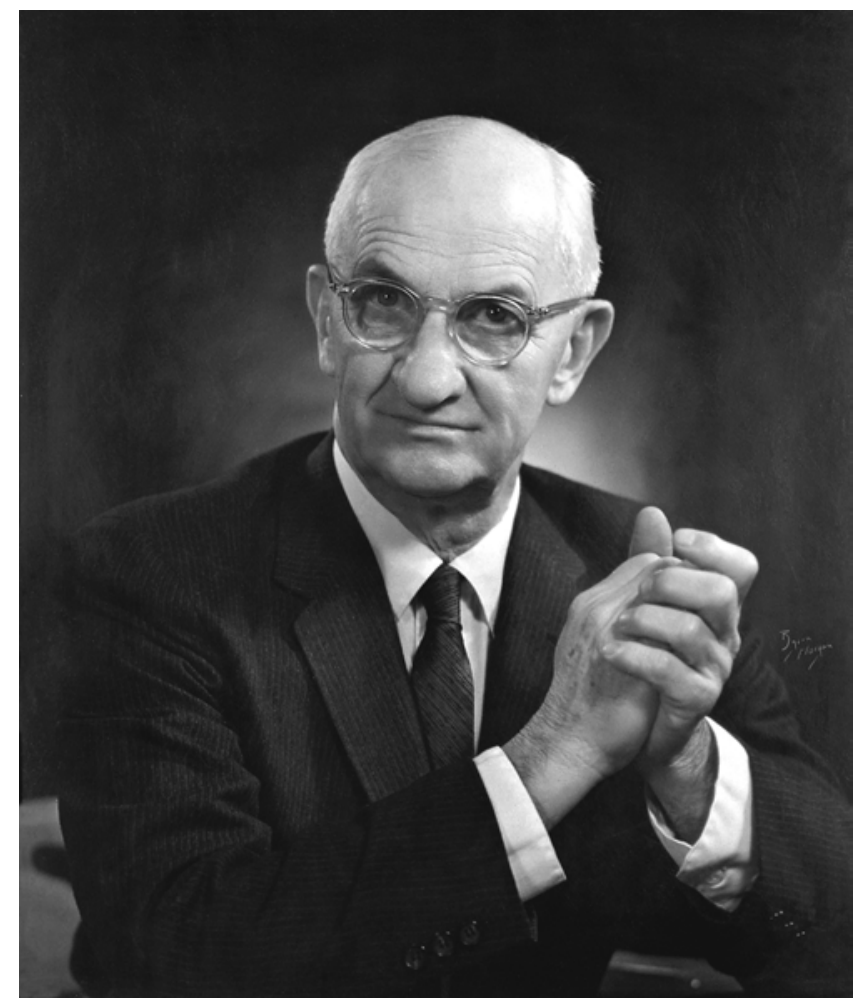

FIG. 2. John J. Morton Jr., the first chair of the Department of Surgery at URMC and a trainee of Harvey Cushing. (Image courtesy of the Department of Surgery, URMC.)

envisioned a similar world-class neurological institute at the University of Rochester. He developed a detailed proposal with architectural drawings for such an institute, but his vision was not realized in his lifetime. Nevertheless, much of Van Wagenen's clinical work recognized that the complexity of neurological diseases necessitated a multidisciplinary approach. In 1954, after 26 years of practice in Rochester, Van Wagenen retired. His early retirement was attributable somewhat to his frustration over the lack of support from URMC leadership for his proposals such as the Cushing library and a neuroscience institute. In 1961, he died from complications of acute cholecystitis. In his will he left a bequest to establish a fund to support the research endeavors of neurosurgical trainees. This fund would many years later become the Van Wagenen Fellowship, managed and organized by the AANS, which annually funds a 1-year research experience for a graduate of a neurosurgical residency program.

\section{Frank Pye Smith (1954-1974)}

Following Van Wagenen's retirement, neurosurgery was made a division of the Department of Surgery. Frank P. Smith (1915-2003) (Fig. 4) was promoted to the rank of assistant professor and made the head of the Division of Neurosurgery. In 1956 Smith recruited Dr. Joseph V. McDonald from Johns Hopkins to join him on the fulltime faculty.

A native of the Rochester area and an honors graduate of local Hobart College, Smith graduated from the Univer-

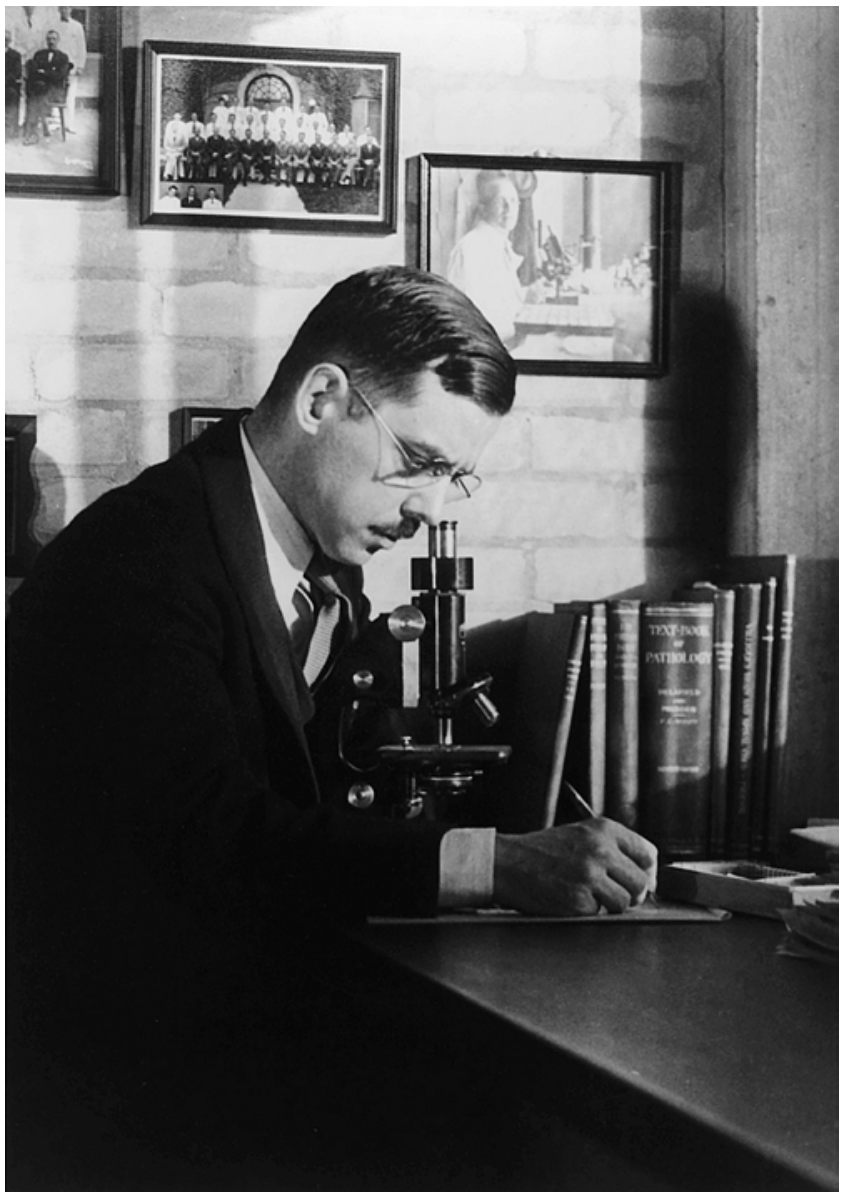

FIG. 3. William P. Van Wagenen, the first chief of Neurosurgery at URMC. (Image courtesy of the Department of Neurosurgery, URMC.)

sity of Rochester Medical School in 1941. He spent a year during medical school working in Whipple's laboratory. After his surgical internship, Smith entered the military, serving as commanding officer of a mobile surgical unit. Assigned to the Normandy invasion with General Patton's Third Army, he was awarded a Purple Heart and three Battle Stars following that engagement. On his return to Rochester, he completed his training in neurological surgery under Van Wagenen, followed by a fellowship at the University of California, San Francisco, under Dr. Howard Naffziger.

While Smith was chief of neurosurgery, he involved himself and his trainees in multiple areas of clinical research; during his tenure, Smith trained 12 neurosurgeons. Three of his trainees (Shige-Hisa Okawara, Thomas Rodenhouse, and Robert Bakos) would go on to serve as faculty in the department.

Smith also took an active interest in organized neurosurgery. He was the first president of the Upstate New York Neurosurgical Society, which was the parent organization of the New York State Neurosurgical Society. He was president of the Neurosurgical Society of America in 1969, and vice president of the Society of Neurological Surgeons in 1974. He also served on the Board of Directors of the AANS and did extensive studies of neurosurgical manpower in the US. 


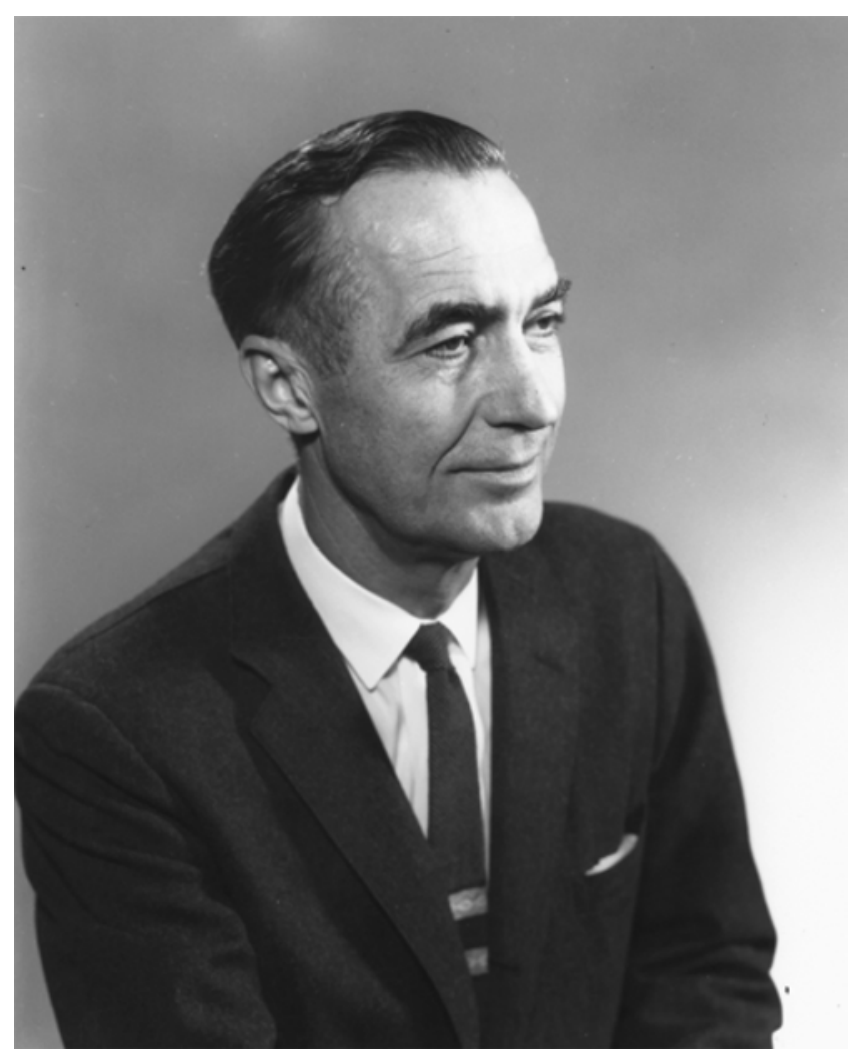

FIG. 4. Frank P. Smith, the second chief of Neurosurgery at URMC. (Image courtesy of the Department of Neurosurgery, URMC.)

After 20 years as chief, Smith moved his practice to Monterey, California. He maintained his link with URMC as a professor emeritus and continued to have a strong interest in the neurosurgery department at URMC. In 1980, Dr. and Mrs. Frank P. Smith endowed a professorial chair in neurological surgery. This was the first such endowed chair within the Department of Surgery at URMC.

Smith was devoted to the growth of neurosurgical research and resident education. In 1999, he advised Van Wagenen's widow Abigail to expand the nearly depleted endowment fund for the Van Wagenen Fellowship. After her death in 2002, a significant bequest to the Van Wagenen Fellowship perpetuated this prestigious award. Inspired by the experiences of Van Wagenen and Cushing, this fellowship funds the research endeavors of 1 neurosurgical resident graduate annually. This fellowship has enhanced the training of many leaders in the field. In recognition of his contributions, Smith was made a permanent member of the Van Wagenen Committee. For this and his many other activities, he was awarded the AANS Distinguished Service Award in 2001.

\section{Joseph V. McDonald (1974-1990)}

Joseph V. McDonald (b. 1925) (Fig. 5), a 1949 graduate of the University of Pittsburgh Medical School and a Johns Hopkins trainee in neurosurgery under Earl Walker (1953-1956), joined Smith as faculty of the Division of Neurosurgery. After Smith's retirement in 1974, McDonald succeeded him as chief.
In 1975, McDonald recruited Dr. Shige-Hisa Okawara (1930-2012), a former University of Rochester trainee, to join the full-time faculty. Following residency, Okawara had completed fellowships in Edinburgh, Scotland, and Copenhagen, Denmark, and had served on the faculty of the University of Iowa. In 1990, shortly before his retirement, McDonald recruited another Rochester trainee, Dr. Webster H. Pilcher, to the division.

While Smith was chief of neurosurgery at URMC, residents of the program had difficulty passing the neurosurgical boards. Because of this, URMC nearly lost its neurosurgery residency program around the time of Smith's retirement. Once he became chief, McDonald took his role as surgical educator very seriously. Over McDonald's tenure, neurosurgical clinical volume expanded and the training program grew to 6 total residents. Resident performance on the boards dramatically improved. In more than 3 decades of service as a faculty member at URMC, McDonald was involved in the training of more than 25 graduates of the URMC program. Each year, the Joseph V. McDonald Excellence in Teaching Award is given to the faculty member, nominated by the residents, who demonstrates outstanding effort in resident teaching and education, in the spirit of the award's namesake.

\section{Eugene D. George, Shige-Hisa Okawara, and Robert V. Maciunas (1990-2001)}

In 1990, at the age of 65 , McDonald retired as chief of the Division of Neurosurgery. Dr. Seymour Schwartz, chair of the Department of Surgery at URMC, selected Dr. Eugene George, formerly chair of neurosurgery at the Walter Reed Army Hospital and director of the US Army neurosurgery residency program, to serve as the second Frank P. Smith Professor and chief of the Division of Neurosurgery. In 1995 Dr. George left Rochester and accepted a position at the University of Texas Southwestern. In 1999, after an interim period during which Dr. Okawara served as acting chief, Dr. Robert J. Maciunas was appointed as the third Frank P. Smith Professor of Neurosurgery. Maciunas recruited additional faculty to the division, expanding the ranks of the full-time faculty to 7 neurosurgeons. Despite this progress, Dr. Maciunas' chairmanship was short-lived and he left URMC in 2001.

\section{Webster H. Pilcher (2002-present)}

After a transitional period, Dr. Pilcher (b. 1950) was appointed chair of the department in 2002. A 1983 graduate of the University of Rochester Medical School and a 1989 graduate of the URMC neurosurgery training program, Pilcher became the fourth Frank P. Smith Professor and chair of the Department of Neurosurgery.

The continued generosity of Dr. Smith resulted in the establishment of departmental status (1998) and research laboratories (2001) for neurosurgery. Under Dr. Pilcher's leadership, a dramatic expansion of the translational research infrastructure of the department was undertaken. The lifeblood of department activities remained resident education. Dr. Robert Bakos (resident, 1973-1977) started as associate program director under Dr. Maciunas and as- 


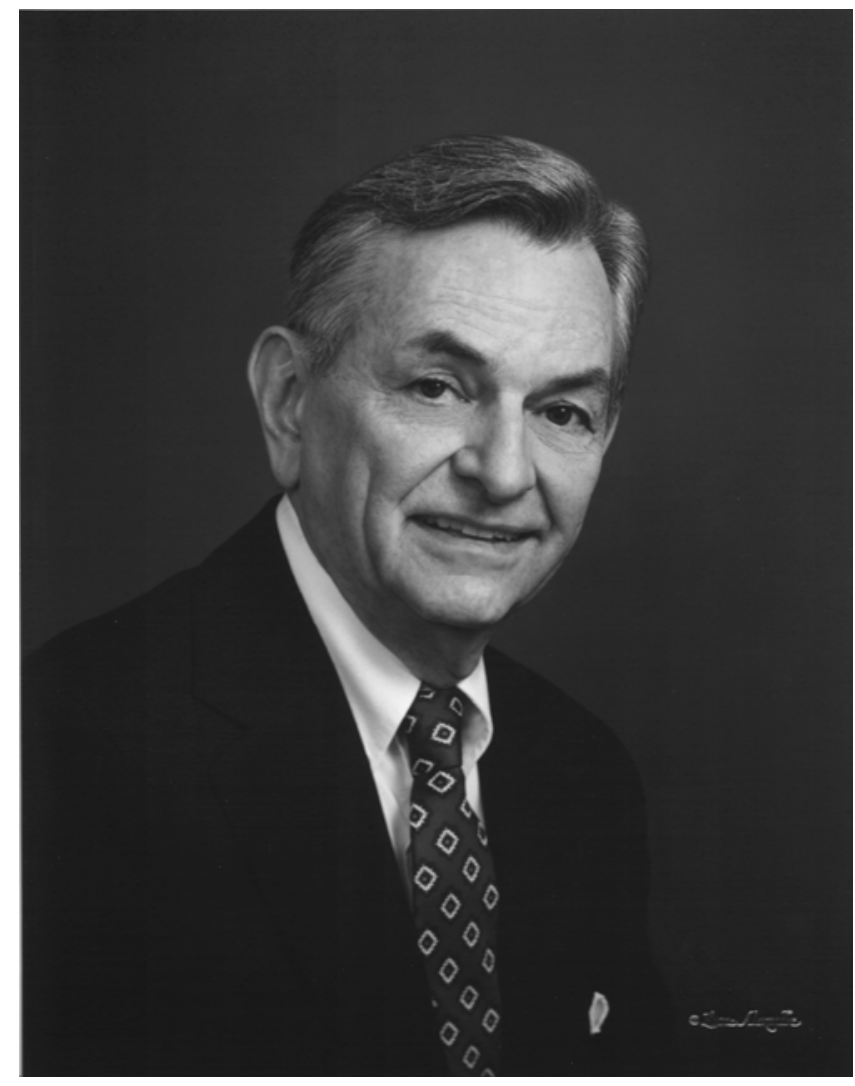

FIG. 5. Joseph V. McDonald, the third chief of Neurosurgery at URMC. (Image courtesy of the Department of Neurosurgery, URMC.)

sumed full directorship in 2001. Shortly after Dr. Pilcher's appointment in 2002, the residency program, which was placed on probationary status during the transitional period prior to his appointment, received a full 5-year accreditation. Over the next several years the resident complement expanded to 2 residents per year. With the incorporation of senior faculty from the community and the recruitment of 9 additional clinical faculty, the surgical volume expanded from 1000 cases to more than 3000 cases per year.

The Department of Neurosurgery has 2 endowed lectureships annually, memorializing its first 2 chiefs. The William Van Wagenen lectureship is delivered in June as a capstone to the academic year, and the Frank P. Smith lecture is held every fall. To date the neurosurgery residency program has graduated more than 80 residents (Table 2) who have gone on to practice neurosurgery all over the country.

\section{Departmental Achievements}

The University of Rochester has a long history of excellence in the neurosciences, with neurosurgery faculty contributing over the years to this reputation. Perhaps one of the most notable achievements was Dr. Van Wagenen's seminal description of the corpus callosotomy, ${ }^{8}$ which paved the way for discoveries about interhemispheric connections that would lead to a Nobel Prize in Medicine. ${ }^{3}$ Dr. Smith was responsible for describing a novel technique of
TABLE 2: Graduates of the URMC neurosurgery residency program*

\begin{tabular}{|c|c|c|c|}
\hline Name & $\begin{array}{c}\text { Residency } \\
\text { Yrs }\end{array}$ & $\begin{array}{c}\text { Chief } \\
Y r\end{array}$ & Location \\
\hline Theodore Trimble & 1934-1937 & 1937 & deceased \\
\hline William Beswick & $1936-1938$ & 1938 & deceased \\
\hline Robert Herren & 1938-1939 & 1939 & deceased \\
\hline Roland Bellows & $1933-1940$ & 1940 & deceased \\
\hline Wilford Risteen & 1939-1942 & 1942 & deceased \\
\hline Jack French & $1938-1943$ & 1943 & deceased \\
\hline Kenneth Livingston & 1942-1943 & 1943 & deceased \\
\hline Frank Smith & $1945-1948$ & 1948 & deceased \\
\hline Preston Weadon & $1949-1951$ & 1951 & deceased \\
\hline Frederick Pitts & $1956-1958$ & 1958 & deceased \\
\hline Henry Stoltmann & 1957-1962 & 1962 & Wellesley, MA \\
\hline Shige-Hisa Okawara & 1959-1964 & 1964 & deceased \\
\hline Robert Mitgang & 1963-1967 & 1967 & Livingston, MT \\
\hline George Yang & 1964-1968 & 1968 & Lopez Island, WA \\
\hline Thomas Klump & 1965-1969 & 1969 & Klamath Falls, OR \\
\hline Jorge Balarezo & 1968-1972 & 1972 & Grosse lle, MI \\
\hline Nettleton Payne & 1967-1972 & 1972 & Atlanta, GA \\
\hline Thomas Rodenhouse & 1969-1973 & 1973 & Rochester, NY \\
\hline Magdy Boulos & 1970-1974 & 1974 & Wilmington, DE \\
\hline Mitchell Weinstein & 1972-1976 & 1976 & Portland, OR \\
\hline Robert Bakos & 1973-1977 & 1977 & Rochester, NY \\
\hline Ramon Cova-Arria & $1975-1978$ & 1978 & Costa Rica \\
\hline Boswell Roberts Jr. & 1974-1979 & 1979 & deceased \\
\hline Joseph Arico & $1975-1980$ & 1980 & deceased \\
\hline Nelson Macedo & $1977-1981$ & 1981 & Rocky Mount, NC \\
\hline Victor Nakkache & $1978-1983$ & 1983 & Wilkes-Barre, PA \\
\hline Philip Marra & 1979-1984 & 1984 & Schenectady, NY \\
\hline Somnath Nair & 1980-1985 & 1985 & Boynton Beach, FL \\
\hline Paul Maurer & 1981-1986 & 1986 & Rochester, NY \\
\hline Walter Faillace & 1982-1987 & 1987 & Bethesda, MD \\
\hline Mark Marchese & 1984-1989 & 1989 & Hickory, NC \\
\hline Webster Pilcher & 1984-1989 & 1989 & Rochester, NY \\
\hline Charles Nussbaum & $1985-1990$ & 1990 & Seattle, WA \\
\hline William Welch & $1986-1991$ & 1991 & Philadelphia, PA \\
\hline George Rusyniak & 1986-1992 & 1992 & Mobile, AL \\
\hline Linda Bland & 1987-1993 & 1993 & Palm Beach Gardens, FL \\
\hline Michael Radley & 1989-1994 & 1994 & Hagerstown, MD \\
\hline Patrick Ireland & 1990-1995 & 1995 & Winchester, VA \\
\hline Paul Peterson & 1991-1996 & 1996 & Knoxville, TN \\
\hline Kevin Mullins & 1992-1997 & 1997 & West Islip, NY \\
\hline Harsimran Brara & 1993-1998 & 1998 & Los Angeles, CA \\
\hline Brian Hoeflinger & 1994-1999 & 1999 & Toledo, $\mathrm{OH}$ \\
\hline Salvatore Palumbo & $1995-2000$ & 2000 & West Islip, NY \\
\hline Shahram Rezaiamiri & 1995-2001 & 2001 & Atlanta, GA \\
\hline Rafael Allende & 1997-2003 & 2003 & Sanford, FL \\
\hline Sandeep Teja & 1998-2004 & 2004 & Charlottesville, VA \\
\hline
\end{tabular}

(continued) 
TABLE 2: Graduates of the URMC neurosurgery residency program* (continued)

\begin{tabular}{lccl}
\hline \multicolumn{1}{c}{ Name } & $\begin{array}{c}\text { Residency } \\
\text { Yrs }\end{array}$ & $\begin{array}{c}\text { Chief } \\
\text { Yr }\end{array}$ & \multicolumn{1}{c}{ Location } \\
\hline Marshall Watson & $1999-2005$ & 2005 & Duluth, MN \\
Pierre Girgis & $2003-2006$ & 2006 & Rochester, NY \\
Jeffrey Tomlin & $2000-2006$ & 2006 & San Diego, CA \\
Stephen Campbell & $2001-2007$ & 2007 & Allentown, PA \\
Patrick Reid & $2002-2009$ & 2008 & West Islip, NY \\
Andrew Wensel & $2001-2009$ & 2009 & Rochester, NY \\
Christian Kaufman & $2006-2010$ & 2010 & Kansas City, MO \\
Arash Farahvar & $2004-2011$ & 2011 & Urbana, IL \\
Angel Boev & $2005-2012$ & 2012 & Rochester, NY \\
Vasillios Dimopolous & $2006-2013$ & 2013 & Miami, FL \\
Henry Kesler & $2006-2013$ & 2013 & Miami, FL \\
\hline
\end{tabular}

* There are gaps in the dates for trainees due to Dr. Van Wagenen's service in the US Army in the 1940s during World War II. In the 1950s, due to Dr. Van Wagenen's early retirement and the transition to Dr. Smith's leadership, there is an additional gap between dates for residents.

thoracic ganglionectomy for relief of intercostal pain after thoracotomy. ${ }^{6}$ During his tenure, McDonald published a series of reports on the endocrinological and autonomic changes in patients with severe brain injuries..$^{9-11} \mathrm{He}$ also developed a successful surgical approach to the heart's autonomic nerve supply to treat patients suffering from prolonged QT syndrome. ${ }^{4}$ Dr. Okawara published more than 40 journal articles in English and Japanese during his career.

In the current era, with the recruitment of outstanding translational researchers, the department has developed vibrant programs in a variety of disease processes. The current Frank P. Smith Professor of Neurosurgery is Dr. Maiken Nedergaard, who is one of the world's preeminent experts in glial biology. Prior to leaving to become the chair of the Department of Physiology and Biophysics at the University of Southern California, Dr. Berislav Zlokovic also conducted high-impact research in the areas of stroke and Alzheimer disease while serving as a professor in the neurosurgery department. In 2011 the department received an endowment from local benefactor Ernest J. Del Monte to create the Del Monte Neuromedicine Institute. The Institute provides a permanent home for neuroscience research programs within a state-of-the-art research building adjacent to the University of Rochester Medical School. This Institute will provide the substrate for the clinical and basic science research in the neurosciences at URMC in the years to come, and fulfills the vision of the Department of Neurosurgery's pioneer, Dr. Van Wagenen.

\section{Acknowledgments}

We thank Dr. Michael Moravan for his assistance in the preparation of this manuscript. We also thank Ms. MaryAnn Ballou for her tireless efforts in gathering and organizing the archives of the Department of Neurosurgery at URMC.

\section{Disclosure}

The authors report no conflict of interest concerning the materials or methods used in this study or the findings specified in this paper.

Author contributions to the study and manuscript preparation include the following. Conception and design: Kimmell. Drafting the article: Kimmell. Critically revising the article: all authors. Reviewed submitted version of manuscript: all authors. Approved the final version of the manuscript on behalf of all authors: Kimmell.

\section{References}

1. Flexner A: Medical education in the United States and Canada. From the Carnegie Foundation for the Advancement of Teaching, Bulletin Number Four, 1910. Bull World Health Organ 80:594-602, 2002

2. Kimmell KT, Petraglia AL, Ballou MA, Pilcher WH: William P. Van Wagenen (1897-1961): pupil, mentor, and neurosurgical pioneer. Historical vignette. J Neurosurg 119:789-795, 2013

3. Mathews MS, Linskey ME, Binder DK: William P. van Wagenen and the first corpus callosotomies for epilepsy. J Neurosurg 108:608-613, 2008

4. Moss AJ, McDonald J: Unilateral cervicothoracic sympathetic ganglionectomy for the treatment of long QT interval syndrome. N Engl J Med 285:903-904, 1971

5. Smith FP: Archival correspondence regarding the origin of the Harvey Cushing Society: the American Association of Neurological Surgeons. J Neurosurg 81:950-955, 1994

6. Smith FP: Trans-spinal ganglionectomy for relief of intercostal pain. J Neurosurg 32:574-577, 1970

7. Van Wagenen WP: A surgical approach for the removal of certain pineal tumors; report of a case. Surg Gynecol Obstet 53: 216-220, 1931

8. Van Wagenen WP, Herren RY: Surgical division of the commisural pathways in the corpus callosum. Relation to spread of an epileptic attack. Arch Neurol Psychiatry 44:740-759, 1940

9. Woolf PD, Hamill RW, Lee LA, Cox C, McDonald JV: The predictive value of catecholamines in assessing outcome in traumatic brain injury. J Neurosurg 66:875-882, 1987

10. Woolf PD, Hamill RW, Lee LA, McDonald JV: Free and total catecholamines in critical illness. Am J Physiol 254:E287E291, 1988

11. Woolf PD, Lee LA, Hamill RW, McDonald JV: Thyroid test abnormalities in traumatic brain injury: correlation with neurologic impairment and sympathetic nervous system activation. Am J Med 84:201-208, 1988

Manuscript submitted December 2, 2013.

Accepted July 2, 2014.

Please include this information when citing this paper: published online August 8, 2014; DOI: 10.3171/2014.7.JNS132658.

Address correspondence to: Kristopher T. Kimmell, M.D., Department of Neurosurgery, University of Rochester Medical Center, 601 Elmwood Ave., Box 670, Rochester, NY 14642. email: kristopher_kimmell@urmc.rochester.edu. 